\title{
Browsing while reading: effects of instructional design and learners' prior knowledge
}

\author{
Thiemo Müller-Kalthoff $\mathrm{f}^{*}$ and Jens Möller ${ }^{\mathrm{b}}$ \\ ${ }^{\mathrm{a}}$ University of Bielefeld, Germany; ${ }^{\mathrm{b}}$ University of Kiel, Germany
}

\begin{abstract}
One of the key reasons that multimedia, and particularly hypertext systems, are gaining in importance is that they inspire hopes of optimizing learners' processes of knowledge construction. The present study is concerned with the respective influence of individual learner variables (i.e. particularly domain-specific prior knowledge) on the use of different design attributes. Thirty-six university students worked through a hierarchically structured two-part hypertext about the psychology of memory under two experimental browsing conditions (reduced versus free browsing). Results show that deeper-level comprehension (i.e. structural knowledge) was predicted by the interaction of experimental condition and prior knowledge, but that simply retaining facts was not. Participants with low prior knowledge performed better on the comprehension test if they had worked on the version with reduced access. Moreover, the version with reduced access helped to reduce feelings of disorientation. The measure of disorientation also appeared to be closely linked with the individual's computer experience, self-concept of computer ability and subject-related interest. The main implications for educational practice relate to the design of an adaptive multimedia and hypertext learning system and the successful learning with it.
\end{abstract}

\section{Introduction}

Although hypertext was 'not purposefully designed for education' (Whalley, 1993, p. 7), but rather for organizing vast amounts of information in databanks, it is being used to an increasing degree in teaching and learning contexts. The non-linear structure of the information presented in such systems (self-contained information units, or nodes, connected by a dynamic network of links) is considered particularly beneficial to learning. This idea is grounded in the extensive contemporary research on instruction and learning, which generally conceptualizes learning as an active, constructive process of building up and changing mental structures (for example, Jonassen, 1991).

\footnotetext{
* Corresponding author. Department of Psychology, University of Bielefeld, Germany, Postfach 10 01 31, D-33501 Bielefeld, Germany. Email: thiemo.mueller-kalthoff@uni-bielefeld.de
} 
Hypertext environments allow learners to work their way through learning material along paths of their own choosing (for example, Plass et al., 1998), thus allowing users to engage in self-directed learning activities and to adapt the learning process to their own needs to an extent that is not supported by classic print media or conventional computer-based systems. Hypertext has often been termed 'non-linear', 'nonsequential' (Nielsen, 1995) or 'multi-linear' (for example, Bolter, 1998) in structure to differentiate it from forms of text with a predetermined structure.

Various empirical studies have already investigated the instructional design (i.e. system features) of such interactive learning systems, and particularly their potential for enhancing global knowledge construction. Where the analysis of individual conditions of knowledge construction in hypertext learning is concerned, however, there is still an urgent need for considerable further research into the underlying processes (Dillon \& Gabbard, 1998; Unz \& Hesse, 1999). Conceived of as a planned (quasiexperimental) research intervention into current innovation and practice, the present study examines how domain-specific prior knowledge impacts on learning outcomes and perceived disorientation when a two-part hypertext learning environment is presented under two browsing conditions (reduced versus free browsing).

\section{Learning with hypertext: problems and possible solutions}

The same qualities of hypertext that are recognized as advantages for learning also generate obstacles to learning while browsing or navigating hypertext. These difficulties fall into two basic categories: problems of disorientation (being lost in hyperspace) and cognitive overload. Both make it difficult to concentrate on the context of a text and thus inhibit deeper-level information processing. Feelings of disorientation result, in particular, when the learner is unable to construct an overview of the hypertext environment. Some of the problems that can lead to disorientation include uncertainty about which node led to the current node or how the current node is situated in relation to the other nodes of the hypertext, difficulty in deciding which node to go to next, and not being sure how to get to a node that one assumes to be contained in the hypertext (cf. Conklin, 1987; Edwards \& Hardman, 1989; McAleese, 1989). Furthermore it is also harder to establish coherence than in linear texts (Plötzner \& Härder, 2001), where phrases such as 'in contrast', 'secondly', 'finally', and so on, help to explain the semantic relationships between successive chunks of a text (van Dijk \& Kintsch, 1983). Browsing or navigating through hypertext makes greater demands on the cognitive system than reading a linear text, and absorbs so many resources that - given the assumed limitations of working memory-learning may be impeded (for example, Chandler \& Sweller, 1991). After visiting a node, learners must decide on one of several links. They must remember the content of previously visited nodes, how to get back to these nodes, which nodes still need to be visited, and so forth.

To respond to the specific cognitive demands of learning with hypertexts, navigational aids in the form of maps or graphical overviews of the document structure are often integrated into hypertext environments. The findings of empirical studies 
investigating the effects of overviews and the structural information they contain on learners' ability to retain or understand material have not been unequivocal, however (for a brief overview, see Müller-Kalthoff \& Möller, 2005). Zellweger (1989) concludes that graphical overviews are especially helpful in smaller hypertexts (for experimental evidence, see Gupta \& Gramopadhye, 1995). In more extensive hypertext environments, one is soon faced with the paradoxical situation that the overviews themselves soon become too sprawling or complex ('visual spaghetti') to give the user a useful insight into the structure of the material (Dillon et al., 1993; Nielsen, 1995). In these cases, other kinds of meaningful representations need to be found, in order to enable the learner to structure the text material in appropriate manner.

In our view, one possible solution lies in reducing the complexity of the structure of nodes and links and 'restricting' access to certain parts of the hypertext. Here, users are not immediately allowed to explore the entire hypertext environment; rather, their movements are initially limited to certain substructures. Within these substructures, which may be 'released' one after the other, for instance, users are able to navigate freely along paths or (hyper)trails (Horn, 1989) of their own choosing, using the hypertext principle. This is a crucial point. For many authors, any restriction of the hypertext structure fundamentally contradicts the principle of non-linearity. Therefore, the 'challenge is to provide paths that are expressive and/or are an integrated adjunct to other links within a hypertext network' (Zellweger, 1989, pp. 1-2). This is not a new debate-either in hypertexts or other learning systems. Zellweger (1989) dealt at length with the 'concept of a path, or ordered traversal of some links in a hypertext' (p. 1) and criticized the inadequate attention given to this matter thus far in theory and practice. Little has changed in this regard. Empirical studies on the learning effects of these aids have been devoted primarily to the influential concept of 'guided tours' (for example, Allison \& Hammond, 1989; Lemahieu, 2002). However, guided tours in particular have only very simple linking structures and impose limitations that lead to predetermined, linear texts - free navigation along paths of one's own choosing is generally not possible.

\section{On the influence of prior knowledge}

Prior knowledge is generally understood to be the factual (declarative) and practical (procedural) knowledge that a person possesses in a given domain (e.g. physics, mathematics, psychology) (Alexander, 1992). With increasing prior knowledge, the individual is better able to establish links with the existing knowledge base and to 'file' new information accordingly. Those studies that deal with the impact of prior knowledge on learning with hypertext focus on the question of whether instructional design has the same effect on all learners, and whether different levels of effectiveness can be predicted on the basis of prior knowledge. This question traditionally belongs to the domain of what is known as 'ATI-Research' (Aptitude Treatment Interactions) (Cronbach \& Snow, 1977).

With regard to the instructional design of (multimedia and hypertext) learning materials, there is an abundance of evidence that the importance of suitable support 
structures increases in proportion to lower levels of prior knowledge in the learner (Mayer, 2001). More precisely, the research group led by Mayer has shown that welldesigned teaching and learning materials are of more benefit to students with low prior knowledge than to those with high prior knowledge in a given domain. The use of elaborate and complex learning aids sometimes actually takes up further cognitive resources (Heiß et al., 2003). Added to this, learners with lower levels of prior knowledge experience more navigation problems than those with a higher level of domain-specific prior knowledge (McDonald \& Stevenson, 1998). Consequently, learners with low prior knowledge benefit from aids giving them a structured overview of the text, and thus facilitating the construction of a coherent text representation (for example, Möller \& Müller-Kalthoff, 2000; Potelle \& Rouet, 2003). Shin et al. (1994), in particular, found that users with little prior knowledge benefited from limited access to the contents of a hypertext (given through a strict hierarchical structure) as opposed to free access to all content areas (provided through a network structure with a diverse number of choices).

The main goal of the present study is thus to test how domain-specific prior knowledge affects learning outcomes and perceived disorientation when a two-part hypertext learning environment is presented under two browsing conditions (reduced versus free browsing; see following Method section for details). Learners with high prior knowledge already have a relatively well-elaborated mental model of the topic, and structural aids can thus be assumed to be of less importance to them. Accordingly, the version with reduced access in the present study is expected to reduce perceived disorientation and to facilitate learning in students with low prior knowledge. The differences between the 'reduced' and 'free' browsing conditions are expected to decrease as the level of prior knowledge increases. Of specific concern is whether this applies equally to both surface-level learning (in the sense of simply retaining information) and deeper-level learning (in the sense of comprehension) (van Dijk \& Kintsch, 1983).

\section{Method}

\section{Sample}

Study participants were 36 students of psychology and education from the University of Bielefeld, Germany, most of them women (67\%). They were aged between 20 and 35 years (mean age $=25.03$ years, standard deviation $=3.27$ ). The majority of the students had been in the university for a longer period of time (mean length of study $=6.6$ semesters, standard deviation $=3.47$ ).

\section{Material}

The hypertext used here is hierarchically structured and deals with the psychology of memory (for example, Möller \& Müller-Kalthoff, 2000), covering 20 central concepts in two main chapters (see Figure 1): 'Temporal Structure of the Memory' and 'Content Structure of the Memory'. The entire hypertext consists of 41 nodes, 

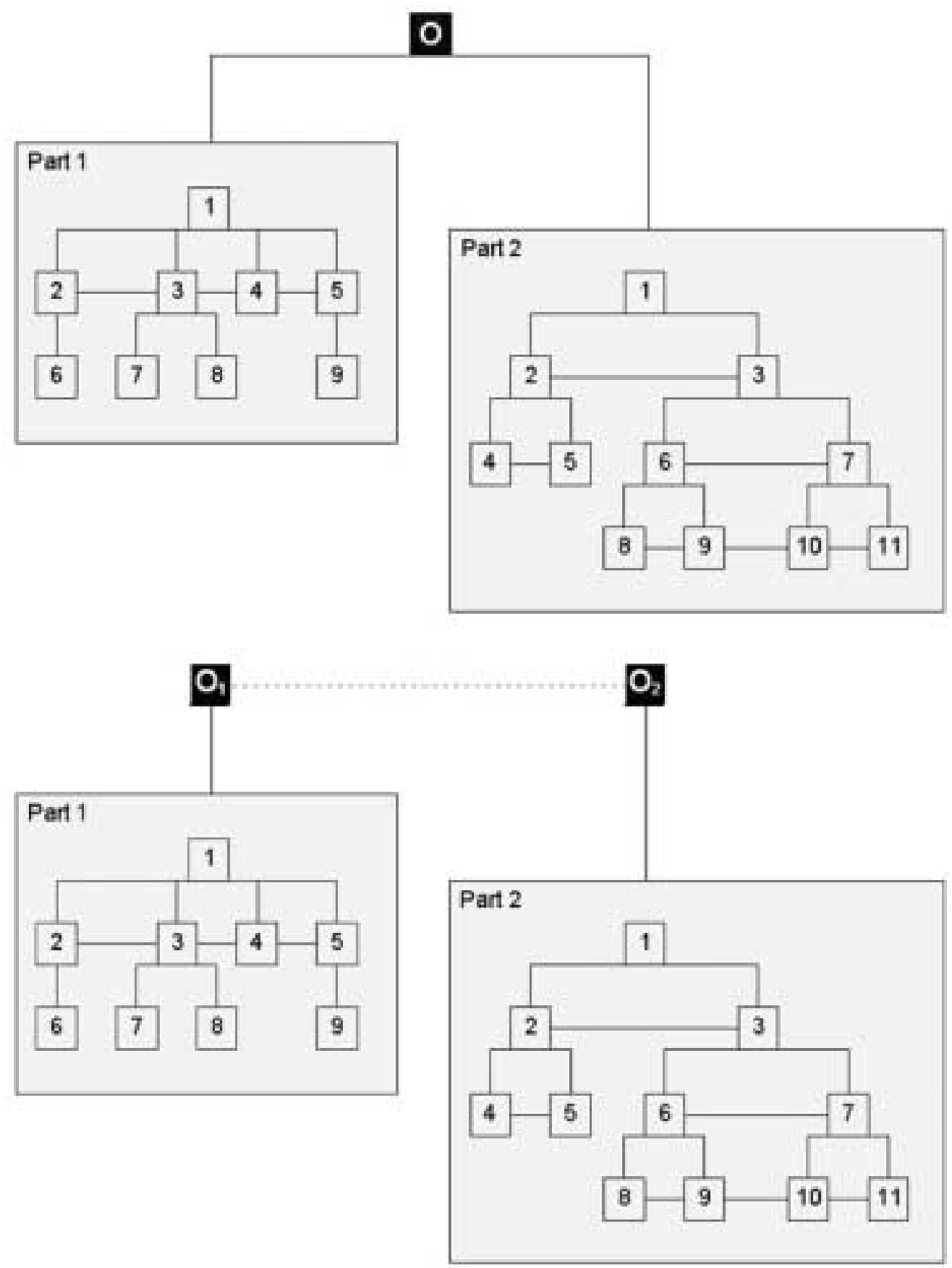

Figure 1. Hierarchical structure of the hypertext and structure of the two experimental conditions: top, free browsing condition; bottom, reduced browsing condition 


\section{วด?}

\section{Koppelung ven neutralem und natïrlichem Relz}

Zunkishst pibt es eine natlinfiche Reiz-Realtions-Verbindung Weil Lemen keine Voraussetaing dieser Verbindung ist, nennt man den Reir (num Beispiel Futter) auch cinen terkonditianierten Prumuse (US) und de Reflexreaktion (Speichelsekretion) eine senkonditioniente Realtion (UR). Ein neutraler Reiz - mun Beispiel ein Glockenton - wird nun mehrmals veiehzeitiz oder in geringem zeitlichem Abstand vor dem unkenditionierten Stimulhs - dem Futter - dargeboten. Nach etwa 10 bis 20 Darbietungen genilgt der Glockenton allein, um die Speichelsekretion auszulssen. Weil Lemes stattgefunden hat, wird der urpsringlich seutrale Reiz nun als konditionierter 2imules (CS) und die Reaktion auf den konditionierten Stimulas als kanditronierte Reaktion (CR) bezeichnet. Besonderes Interesse ist spliter vor allem einer Sehnecke entgegengebracht worden: Aplysia, die sich aufgrund ihres cinfachen Nervensystems besonders gut zar Untersuchung Kassischer Konditionienungsvorgänge cignet.

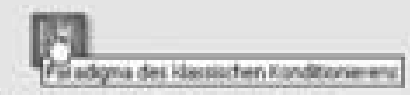
Parndigma des Hlassischen Kenditionierens

Figure 2. Example content page of the hypertext with one embedded link, showing the typical page layout and functions (black and white screenshot of the colored original)

nine figures, and roughly 3400 words. The two chapters are approximately the same size, with 19 versus 22 nodes and 1650 versus 1750 words, respectively.

The hypertext structure takes the form of unidirectional embedded links. Additionally, users can move directly to the central concepts by clicking on the respective titles in a graphical overview (O). Figure 2 shows an example of a typical content page from the hypertext environment. Buttons for the functions 'backtrack' (to the nodes read previously; chronological backtrack), 'overview' and 'help' (with the functions) are positioned at the head of each node. Each node is presented on a single screen page, so that no scrolling is necessary. Only one node can be displayed at a time to avoid the risk of cognitive overload from viewing several windows simultaneously. Nodes containing a link to a figure also feature a 'figure' button at the end of the page.

\section{Overview of experimental design}

In this study, two experimental conditions (reduced versus free browsing; see later) were used, with one version of the same hypertext being prepared for each condition. Participants were allocated to one of the two experimental conditions at random. In 
addition to the experimental factor, the learner variable prior knowledge was included as a predictor. Prior knowledge was treated as continuous variable in the statistical analyses. Participants' scores on a test tapping factual and structural knowledge that was administered after they had worked through the hypertext served as the dependent variable. The level of disorientation perceived by the participants as they worked on the hypertext was also assessed. Additional individual factors were recorded as control variables (computer experience, self-concept of computer-related ability, subject-related interest, learning strategies). The variables used in the study are now described in greater detail.

\section{Experimental factor: browsing condition}

Figure 1 illustrates the implementation of the two experimental conditions. One group of participants $(n=20)$ was given access to both parts of the hypertext from the outset ('free browsing condition'; see top of Figure 1). For those in the 'reduced browsing condition' $(n=16)$, in contrast, access was initially restricted to one part of the hypertext, participants being directed to the other part after one-half of the allocated time had elapsed. They were then able to move between the two parts of the hypertext by clicking on the chapter headings $\left(\mathrm{O}_{1}, \mathrm{O}_{2}\right.$; see dashed line in Figure 1).

The sequence in which participants in the reduced browsing condition worked on the two parts of the hypertext was controlled. One-half began with part $1(n=9)$, and the other half with part $2(n=7)$. These two groups did not differ in terms of their prior knowledge or the dependent variables (all $t(14)<1.31$, not significant).

\section{Test of learning outcomes and measurement of prior knowledge}

Twelve multiple-choice questions were administered to assess learning outcomes after the students had worked through the hypertext. One or more of the four answers to each multiple-choice question were classified as correct. The position of the correct answer(s) was varied at random. One point was given for each correct answer chosen by the participant. Because some questions had more than one correct answer, the highest possible score was 30 . One-half of the questions tapped participants' factual knowledge in the domain of 'Learning and Memory'. These questions could be answered simply by retrieving facts or names, and the correct answers could be drawn directly from the text. Up to 13 points could be scored on this part of the test. These factual knowledge questions were also administered at the beginning of the experiment, where they served as indicators of the participants' prior knowledge. In order to minimize recognition effects, the order of the items was changed. The other half of the questions tapped structural knowledge. To answer these questions, participants needed to be able to recognize relationships between different units and/or draw the appropriate conclusions. (For example, 'What kind of learning is involved in operant conditioning?' Response options: (a) implicit learning, (b) explicit learning, (c) associative learning, (d) procedural learning.) Up to 17 points could be scored on this part 
of the test. The answers could not be drawn directly from the text, but required a certain understanding of the material.

\section{Disorientation}

Perceived disorientation was measured using 11 items with four response categories (from $1=$ 'strongly disagree' to $4=$ 'strongly agree'). Some of these items were formulated following the scale from Beasley and Waugh (1995). Sample items for the disorientation scale include 'I often felt lost in the text' and 'I was often unsure about where I'd already been'.

\section{Control variables}

Four further individual variables were included in this study as control variables: the participants' computer experience (five items, e.g. 'I have already worked with hypertexts'), their self-concept of computer-related ability (four items, e.g. 'I have difficulty understanding a lot of things that relate to computers'), their subjectrelated interest (four items, e.g. 'I enjoy learning about the topic memory and learning') and their learning strategies (five items, e.g. 'I tried to make connections between the content of the hypertext and the knowledge that I already had on the topic'). Each statement offered the subject four possible answers (from $1=$ 'strongly disagree' to $4=$ 'strongly agree'). The self-concept of computer-related ability was assessed as a generalized appraisal of one's own capacity to work with computers (following Möller \& Köller, 2001). The operationalization of the scale of learning strategies was undertaken in accordance with five items from the LIST inventory of students' learning strategies (Wild \& Schiefele, 1994). The investigation focused on learning activities that aim for a deeper understanding of the learning material. In contrast to what is typically found in the literature, the learning strategies were not recorded as a habitual measure, but rather as retrospectively reported strategies used during learning ('actual strategies').

\section{Procedure}

After an introduction, a questionnaire tapping prior knowledge and the control variables of computer experience, self-concept and interest was administered. The online part of the experiment then began with a short introduction to the basic principles of hypertext, a description of the hypertext used in the experiment and information about the experimental procedure. The participants were then given 30 minutes to work through the hypertext. This time limit made it possible to compare individual performances and to relate these to the independent variables. While working on the hypertext, the navigational behavior of the subjects was recorded by the computer. Participants were instructed to study the hypertext carefully, and told they would be asked questions about it. Afterwards, the test of learning outcomes and the disorientation and the learning strategies scale were administered. 


\section{Results}

Table 1 presents the means and standard deviations of the variables under consideration for the 'reduced browsing' and 'free browsing' groups. As expected, correlation analyses revealed a significant relationship between the two indicators of learning outcomes $(r(36)=0.59, p<0.001)$. Prior knowledge did not correlate with perceived disorientation. Overall, however, strong positive correlations were found between prior knowledge and the variables factual and structural knowledge $(r(36)=0.72$ and 0.57 , respectively; both $p<0.001$ ), as had been expected. Higher levels of disorientation were only weakly associated with lower levels of factual $(r(36)=-0.17)$ and structural knowledge $(r(36)=-0.21)$. The observed correlations did not reach the level of significance. No gender differences were discerned in this study (all $t(34)<$ 1.62 , not significant), but there were significant differences in the prior knowledge of participants who worked on the reduced browsing version (mean $=6.75$, standard deviation $=1.48$ ) and those exposed to the free browsing condition (mean $=4.40$, standard deviation $=1.64 ; t(34)=4.46, p<0.001)$.

In order to take these differences in prior knowledge into account in the analyses, regression analyses were run to examine the effects of prior knowledge on learning outcomes and perceived disorientation in the reduced and free browsing groups. Table 2 presents the unstandardized regression coefficients for predictors entered simultaneously in the total equation. The experimental factor $(0=$ free browsing, $1=$ reduced browsing), the learner variable (prior knowledge) and the interaction of the two variables (the product term) were entered as predictors.

\section{Effects on learning}

The predictors explained a total of 55\% of the variance in factual knowledge and $49 \%$ of the variance in structural knowledge (see Table 2 for the $F$ values). The regression analysis showed that, as had been expected, prior knowledge was a significant predictor of performance on the tests of factual and structural knowledge. For factual knowledge, there was no significant main effect of the browsing condition and no significant interaction effect of browsing condition and prior knowledge. The experimental factor did prove to be a significant predictor of deeper-level comprehension, however. Participants exposed to the reduced browsing version scored higher on the structural knowledge test than their peers who had worked on the free browsing

Table 1. Means (standard deviations) of the variables under consideration

\begin{tabular}{lccrrr}
\hline & & \multicolumn{4}{c}{ Variable } \\
\cline { 3 - 6 } Group & $n$ & $\begin{array}{c}\text { Prior } \\
\text { knowledge }\end{array}$ & $\begin{array}{c}\text { Factual } \\
\text { knowledge }\end{array}$ & $\begin{array}{c}\text { Structural } \\
\text { knowledge }\end{array}$ & Disorientation \\
\hline Reduced browsing condition & 16 & $6.75(1.48)$ & $9.25(1.77)$ & $12.19(2.48)$ & $17.06(4.20)$ \\
Free browsing condition & 20 & $4.40(1.64)$ & $6.40(2.19)$ & $9.30(2.11)$ & $19.00(4.54)$ \\
Total & 36 & $5.44(1.95)$ & $7.67(2.45)$ & $10.58(2.68)$ & $18.14(4.44)$ \\
\hline
\end{tabular}


Table 2. Dependent variables as functions of the experimental factor and of the learner variable prior knowledge (linear regression)

\begin{tabular}{|c|c|c|c|c|c|c|}
\hline \multirow[b]{2}{*}{ Predictors } & \multicolumn{2}{|c|}{ Factual knowledge $^{\mathrm{a}}$} & \multicolumn{2}{|c|}{ Structural knowledge ${ }^{\mathrm{b}}$} & \multicolumn{2}{|c|}{ Disorientation $^{\mathrm{c}}$} \\
\hline & $b$ & $\begin{array}{l}\text { Standard } \\
\text { error }\end{array}$ & $b$ & $\begin{array}{l}\text { Standard } \\
\text { error }\end{array}$ & $b$ & $\begin{array}{l}\text { Standard } \\
\text { error }\end{array}$ \\
\hline Browsing condition & 0.46 & 0.30 & $0.78^{\star}$ & 0.32 & $-0.89^{\star}$ & 0.42 \\
\hline Prior knowledge & $0.58^{\star \star \star}$ & 0.15 & $0.34^{\star}$ & 0.16 & 0.35 & 0.21 \\
\hline $\begin{array}{l}\text { Browsing condition } \mathrm{x} \text { Prior } \\
\text { knowledge }\end{array}$ & 0.02 & 0.15 & $-0.42^{\star}$ & 0.16 & 0.14 & 0.21 \\
\hline
\end{tabular}

$n=36 . b$, unstandardized regression coefficient for predictors entered simultaneously in the total equation. Standardized values were computed for the dependent variables and the learner variable; the coding of the experimental factor is given in the text. ${ }^{\star} p<0.05,{ }^{\star \star \star} p<0.001$.

${ }^{a}$ Result for the total equation: $F(3,32)=13.26, p<0.001$

${ }^{\mathrm{b}}$ Result for the total equation: $F(3,32)=10.33, p<0.001$

${ }^{\mathrm{c}}$ Result for the total equation: $F(3,32)=1.57$, not significant.

version. Most interestingly, the interaction effect here was also statistically significant $(b=-0.42, p<0.05)$.

To further analyze the interaction effect on structural knowledge, the regression analyses were repeated separately for the reduced and free browsing experimental groups. The regression lines are shown in Figure 3. In the reduced browsing group, no relationship was found between prior knowledge and the score on the structural knowledge test $(r(16)=-0.10$, not significant). In the free browsing group, in contrast, there was a strong positive correlation between these two variables $(r(20)=$ $0.76, p<0.001)$ : higher prior knowledge scores were associated with higher structural knowledge scores.

This means that participants in the condition with (initially) reduced access performed equally well on the structural knowledge questions, irrespective of their prior knowledge. In the condition with free access from the outset, however, the score on the structural knowledge test was very much dependent on the level of prior knowledge. The slopes of the two regression lines are consistent with the assumed interaction.

\section{Level of disorientation}

The experimental factor was a significant predictor for the level of perceived disorientation, with those using the reduced browsing version experiencing less disorientation. There was no significant main effect of prior knowledge, and no interaction effect. The predictors explained a total of $13 \%$ of the variance (see Table 2 for the $F$ value).

\section{Navigational behavior}

In total, there was no significant difference in navigational behavior between the two experimental groups. Both groups viewed nearly the same number of pages on average 


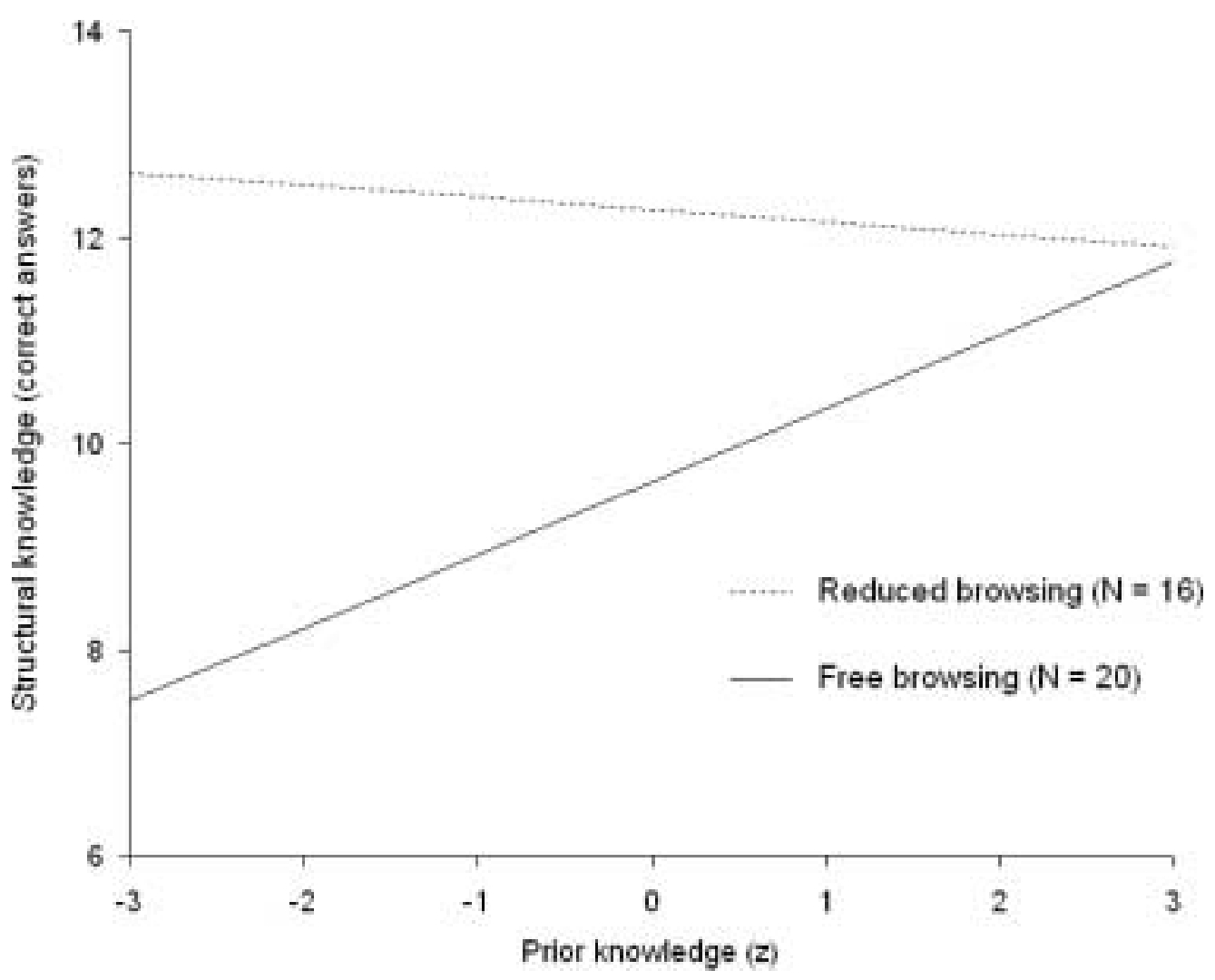

Figure 3. Structural knowledge as a function of the learner variable prior knowledge (linear regression), computed separately for the two experimental groups

while working on the hypertext (free browsing, mean $=93.5$ versus reduced browsing, mean $=96.3 ; t(34)=-0.32$, not significant $)$. This pattern continues also when the activity on part A ( 35.7 versus $40.6 ; t(34)=-1.04$, not significant) and part B (43.5 versus $41.1 ; t(34)=0.43$, not significant) of the hypertext are examined separately. It is worth noting that the subjects viewed an average of 19.6 pages (free browsing) versus 19.5 pages (reduced browsing) repeatedly (i.e. at least two times), while they did not view 4.9 versus 5.2 of the 41 pages of hypertext even once. The average number of times the overview page was viewed was slightly higher under the reduced browsing condition $($ mean $=30.9)$ than under the free browsing condition $($ mean $=24.7)$. However, this difference does not turn out to be statistically significant $(t(34)=1.33$, not significant).

\section{On the influence of the control variables}

The results reveal that there was no significant correlation between prior knowledge and any of the four control variables $(-0.22<r(36)<0.13$, not significant). In several studies, subject-related interest and prior knowledge have been highly correlated (and partly confounded) (cf. Alexander et al., 1994); a similar correspondence did not 
emerge clearly in this study. Likewise, no significant relation was found between the control variables and the learning indicators. Only the self-concept of computerrelated ability produced a moderately positive correlation with the level of facts retained $(r(36)=0.28, p=0.094)$ and structural knowledge $(r(36)=0.31, p=0.069)$. These results suggest in general that relations between prior knowledge and learning achievement cannot be traced back to differences in the control variables.

In contrast, there were significant negative correlations between the control variables (with the exception of the variable 'learning strategies') and perceived disorientation: computer-related experience, $r(36)=-0.34, p<0.05$; self-concept of computer-related ability, $r(36)=-0.50, p<0.01$; and subject-related interest, $r(36)$ $=-0.52, p=0.001$. As was to be expected, significant correlations between the control variables are also evident: interest correlated positively with experience, $r(36)=0.65$, $p<0.001$; self-concept, $r(36)=0.44, p<0.01$; and learning strategies, $r(36)=0.34$, $p<0.05$. Likewise, experience and self-concept $(r(36)=0.68, p<0.001)$ and experience and learning strategies $(r(36)=0.43, p<0.01)$ showed a positive correlation.

\section{Discussion}

Our results confirm the well-documented finding that prior knowledge about the topic at hand is a powerful individual predictor of learning outcomes and should always be controlled for in studies relating to learning with hypertexts. As was to be expected (for example, Lawless \& Kulikowich, 1998; Müller-Kalthoff \& Möller, 2003), participants with high prior knowledge scored much better overall on both retaining facts and understanding content than participants with low prior knowledge. In this study, stronger relations were found for surface-level learning (knowledge of facts). It is possible that this results partly from operationalizing prior knowledge as factual knowledge.

Interestingly, deeper-level comprehension (i.e. the acquisition of structural knowledge) was significantly affected by the interaction of browsing condition and prior knowledge in this study. Prior knowledge played a far less important role for learners in the reduced browsing condition than for those in the free browsing condition. The version with free access from the outset posed particular problems for participants with low prior knowledge, who benefited from being given a structured (initially reduced) view of the contents. It can be assumed that an initial isolated presentation, being less complex, requires fewer cognitive capacities from learners who thus can more easily build subschemes of individual elements. In a second phase, these elements could then be successfully integrated (cf. Pollock et al., 2002). This result is in line with the previous findings on the influence of prior knowledge that were outlined in the introductory section (for example, Shin et al., 1994). Given the critique leveled at ATI-Research in the 1980s, it seems prudent that contemporary research makes use of new designs and methods of measurement to take individual learning variables into consideration (Plass, 2005).

In line with our expectations, the reported differences only emerged for structural knowledge. In other words, there was only a significant interaction of prior knowledge 
and browsing condition when it was not a case of simply retaining facts, but of understanding the material at a deeper level. Thus, it is important that the outcomes of learning processes be assessed in terms of deeper-level processing as well as simply retaining facts (Kintsch, 1998). Newer studies on hypertext learning (for example, Hofman \& van Oostendorp, 1999; Müller-Kalthoff \& Möller, 2005) indicate that when inquiring into both facts and deeper connections, it seems reasonable to differentiate further between outcomes at the macro-level (key concepts) and the microlevel (details) of the text.

It can be assumed that the slightly lower levels of disorientation reported by participants in the reduced browsing condition also contributed to their improved performance. It is worth mentioning, moreover, that the measure of disorientation is not related to the level of prior knowledge a subject brings to the situation, but much more with other individual learner variables. Accordingly, it seems that a lower level of disorientation is closely associated with a higher level of computer experience, a higher self-concept of computer-related ability and a higher interest in the subjectmatter at hand.

\section{Conclusions}

The implications of our findings for educational practice pertain primarily to the design and implementation of adaptive hypertext and multimedia systems in the learning context. Generally speaking, it makes sense to ensure that structures are not overly complicated at introductory levels. As proposed, a useful way of limiting the complexity of a hypertext structure could be restricting access to certain substructures (e.g. single modules) or to information based on a certain criterion (such as general information versus specific information) and thus providing learners with a more structured view of the content. Similarly, research on 'information-filtering' in relation to information retrieval calls for 'more attention on receiving information-the process of controlling and filtering information that reaches the persons who must use it' (Loeb \& Terry, 1992, p. 28). The learner would be shown the relevant nodes and links and allowed to navigate along them at will, without having to follow predetermined paths, as is the case in 'guided tours'. This is, in our view, a significant point. Many authors still believe that restrictions on the hypertext structure contradict one of the fundamental principles of hypertext. This often leaves room for only two alternatives: either wholly free navigation or a predetermined navigational structure, such as a 'guided tour'. Our work seeks to call attention to further possibilities that can be found 'in between' these two extremes.

The significance of learner variables for this question becomes particularly apparent in the context of research findings that show that learners with a low level of prior knowledge and/or lesser cognitive abilities profit from instructional support in learning materials (for example, Mayer, 2001). Our results confirm this. Whereas novice learners need a certain amount of structural support, learners with prior knowledge on the topic could be directed to a higher level (or given access to the whole structure) more rapidly. As shown earlier, this is particularly relevant when more complex 
demands are being placed on the learners. At each stage of the learning process, learners can be given the appropriate form of support. Moreover, at successive stages, they can be offered new and/or more in-depth perspectives on material they have already covered (Shapiro, 2000). Given the state of empirical research, however, firm conclusions can as yet only be drawn with respect to a few individual factors (such as prior knowledge and learning and study strategies). There is still need for considerable further research here.

Future studies should take these additional variables into account: first as control variables (as this study has done), and second to test for interactions of the variables among themselves and with different instructional design models. The present study was a controlled quasi-experimental research intervention involving a relatively small (41-node) hypertext learning environment. Questions arise regarding the ecological validity of this approach, which suggests that exploring whether these findings hold true in real learning situations would be valuable, as would testing a larger sample and different groups of individuals (other than students of psychology and education).

It is clear that the wealth of influencing factors makes it impossible to formulate one simple and overarching solution (Möller \& Müller-Kathoff, 2000). However, a partial solution can be found in attempting to strike a balance between selected design and learner variables.

\section{References}

Alexander, P. A. (1992) Domain knowledge: evolving issues and emerging concerns, Educational Psychologist, 27, 33-51.

Alexander, P. A., Kulikowich, J. M. \& Jetton, T. L. (1994) The role of subject-matter knowledge and interest in the processing of linear and nonlinear texts, Review of Educational Research, 64, 201-252.

Allison, L. \& Hammond, N. (1989) A learning support environment: the hitch-hiker's guide, in: R. McAleese (Ed) Hypertext: theory into practice (Norwood, NJ, Ablex), 62-74.

Beasley, R. E. \& Waugh, M. L. (1995) Cognitive mapping architectures and hypermedia disorientation: an empirical study, fournal of Educational Multimedia and Hypermedia, 4, 239-255.

Bolter, J. D. (1998) Hypertext and the question of visual literacy, in: D. Reinking, M. C. McKenna, L. D. Labbo \& R. D. Keiffer (Eds) Handbook of literacy and technology: transformations in a post-typographic world (Mahwah, NJ, Lawrence Erlbaum), 3-13.

Chandler, P. \& Sweller, J. (1991) Cognitive load theory and the format of instruction, Cognition and Instruction, 8, 293-332.

Conklin, J. (1987) Hypertext: an introduction and survey, IEEE Computer, 20, 17-41.

Cronbach, L. J. \& Snow, R. E. (1977) Aptitudes and instructional methods (New York, Irvington).

Dillon, A. \& Gabbard, R. (1998) Hypermedia as an educational technology: a review of the quantitative research literature on learner comprehension, control and style, Review of Educational Research, 68, 322-349.

Dillon, A., McKnight, C. \& Richardson, J. (1993) Space-the final chapter or why physical representations are not semantic intentions, in: C. McKnight, A. Dillon \& J. Richardson (Eds) Hypertext: A psychological perspective (New York, Ellis Horwood), 169-191.

Edwards, D. M. \& Hardman, L. (1989) 'Lost in hyperspace': cognitive mapping and navigation in a hypertext environment, in: R. McAleese (Ed) Hypertext: theory into practice (Norwood, NJ, Ablex), 105-125. 
Gupta, M. \& Gramopadhye, A. K. (1995) An evaluation of different navigational tools in using hypertext, Computers and Industrial Engineering, 29, 437-441.

Heiß, A., Eckhardt, A. \& Schnotz, W. (2003) Self-regulation and instructional guidance in learning from hypermedia, German fournal of Educational Psychology, 17, 211-220.

Hofman, R. \& van Oostendorp, H. (1999) Cognitive effects of a structural overview in a hypertext, British Fournal of Educational Technology, 30, 129-140.

Horn, R. E. (1989) Mapping hypertext: the analysis, organization, and display of knowledge for the next generation of on-line text and graphics (Waltham, MA, Information Mapping).

Jonassen, D. H. (1991) Objectivism versus constructivism: do we need a new philosophical paradigm?, Educational Technology Research and Development, 39, 5-14.

Kintsch, W. (1998) Comprehension: a paradigm for cognition (Cambridge, Cambridge University Press).

Lawless, K. A. \& Kulikowich, J. M. (1998) Domain knowledge, interest and hypertext navigation: a study of individual differences, Fournal of Educational Multimedia and Hypermedia, 7, 51-69.

Lemahieu, W. (2002) Context-based navigation in the Web by means of dynamically generated guided tours, Computer Networks, 39, 311-328.

Loeb, S. \& Terry, D. (1992) Information filterimg, Communications of the ACM, 35, 26-28.

Mayer, R. E. (2001) Multimedia learning (Cambridge, Cambridge University Press).

McAleese, R. (1989) Navigation and browsing in hypertext, in: R. McAleese (Ed) Hypertext: theory into practice (Norwood, NJ, Ablex), 6-44.

McDonald, S. \& Stevenson, R. J. (1998) Effects of text structure and prior knowledge of the learner on navigation in hypertext, Human Factors, 40, $18-27$.

Möller, J. \& Köller, O. (2001) Dimensional comparisons: an experimental approach to the internal/external frame of reference model, fournal of Educational Psychology, 93, 826-835.

Möller, J. \& Müller-Kalthoff, T. (2000) Learning with hypertext: the impact of navigational aids and prior knowledge, German Fournal of Educational Psychology, 14, 116-123.

Müller-Kalthoff, T. \& Möller, J. (2003) The effects of graphical overviews, prior knowledge, and self-concept on hypertext disorientation and learning achievement, fournal of Educational Multimedia and Hypermedia, 12, 117-134.

Müller-Kalthoff, T. \& Möller, J. (2005) The effects of different graphical overviews on hypertext learning achievement, German fournal of Educational Psychology, 19, 49-60.

Nielsen, J. (1995) Multimedia and hypertext: the internet and beyond (San Diego, Academic Press).

Plass, J. L. (2005) Current trends in research on hypertext/hypermedia systems: commentary on the contributions in this special issue, German fournal of Educational Psychology, 19, 77-83.

Plass, J. L., Chun, D. M., Mayer, R. E. \& Leutner, D. (1998) Supporting visual and verbal learning preferences in a second-language multimedia training environment, fournal of Educational Psychology, 90, 25-36.

Plötzner, R. \& Härder, J. (2001) Supporting the processing of external representations-learning with hyper texts, Unterrichtswissenschaft, 29, 367-384.

Pollock, E., Chandler, P. \& Sweller, J. (2002) Assimilating complex information, Learning and Instruction, 12, 61-86.

Potelle, H. \& Rouet, J.-F. (2003) Effects of content representation and readers' prior knowledge on the comprehension of hypertext, International fournal of Human-Computer Studies, 58, 327-345.

Shapiro, A. M. (2000) The effect of interactive overviews on the development of conceptual structure in novices learning from hypermedia, fournal of Educational Multimedia and Hypermedia, 9, 57-78.

Shin, E. C., Schallert, D. L. \& Savenye, W. C. (1994) Effects of learner control, advisement, and prior knowledge on young students' learning in a hypertext environment, Educational Technology Research and Development, 42, 33-46.

Unz, D. C. \& Hesse, F. W. (1999) The use of hypertext for learning, fournal of Educational Computing Research, 20, 279-295. 
van Dijk, T. \& Kintsch, W. (1983) Strategies of discourse comprehension (New York, Academic Press).

Wild, K.-P. \& Schiefele, U. (1994) Learning strategies of university students: factor structure and reliability of a new questionnaire, Zeitschrift für Differentielle und Diagnostische Psychologie, 15, 185-200.

Whalley, P. (1993) An alternative rhetoric for hypertext, in: C. McKnight, A. Dillon \& J. Richardson (Eds) Hypertext: a psychological perspective (New York, Ellis Horwood), 7-17.

Zellweger, P. T. (1989) Scripted documents: a hypermedia path mechanism, in: Proceedings of Hypertext'89 (New York, ACM), 1-14. 